(Song, PI) funded by the National Institute of Nursing Research, National Institutes of Health, USA.

Disclosure of Interests: Laura P. Kimble: None declared, Arezou Khosroshahi Consultant of: Have received honorarium for advisory board but has no relationship with this work., Grant/research support from: Have received a research grant from Pfizer; but has no relationship with this work., Ronald C. Eldridge: None declared, Glenna S. Brewster: None declared, Nicole S. Carlson: None declared, Elizabeth J. Corwin: None declared

DOI: 10.1136/annrheumdis-2021-eular.491

\section{POS0174 IMMUNOPHENOTYPE OF SJÖGREN'S SYNDROME AND SYSTEMIC LUPUS ERYTHEMATOSUS PATIENTS IDENTIFIED TWO ENDOTYPES WITH POTENTIAL THERAPEUTIC IMPLICATIONS}

L. Martin-Gutierrez ${ }^{1,2}$, J. Peng ${ }^{1,2}$, G. Robinson ${ }^{1,2}, \mathrm{M} \mathrm{Naja}^{2,3}$, H. Peckham ${ }^{2}$, W. Wu ${ }^{2}$, D. Isenberg ${ }^{1,3}$, E. Jury ${ }^{1}$, C. Ciurtin ${ }^{2,3} .{ }^{1}$ Centre for Rheumatology Research, Department of Medicine, London, United Kingdom; ${ }^{2}$ Centre for Adolescent Rheumatology Versus Arthritis, Department of Medicine, London, United Kingdom; ${ }^{3}$ University College London Hospitals, Department of Rheumatology, London, United Kingdom

Background: Primary Sjögren's syndrome (pSS) and systemic lupus erythematosus (SLE) are chronic autoimmune rheumatic diseases (ARDs) that share a strong female gender bias, as well as genetic, clinical and serological characteristics. Although significant progress has been made in improving treatment and patient related outcomes in pSS and SLE, there is a need for improved early diagnosis, adequate therapy monitoring, treatment of refractory manifestations and strategies to address co-morbidities. However, the results of many clinical trials are disappointing, and nobiologic treatments are licensedin pSS, while few are available for SLE patients with refractory disease.

Objectives: Identifying shared immunological features between patients with pSS and SLE that could lead to better treatment selection using a stratification approach.

Methods: Immune-phenotyping of 29 immune-cell subsets in peripheral blood from patients with pSS $(n=45)$, SLE $(n=29)$ and secondary SS associated with SLE (SLE/SS) $(n=14)$ with low disease activity or in clinical remission, and sex-matched healthy controls $(n=31)$, was performed using flow cytometry. Data were analysed using logistic regression and multiple t-tests andsupervised machine learning (balanced random forest-BRF, sparse partial least squares discriminant analysis-sPLS-DA). Patients were stratified by k-means clustering. Clinical trajectories were analysed over 5 year follow-up.

Results: Comparing the immune profile of pSS and SLE patients using a variety of statistical and machine learning (ML) approaches, identified very few statistically significant differences between the two cohorts despite patients having a different clinical presentation and diagnosis. Thus, we hypothesised that immune-based subtypes could be shared between pSS, SLE and SLE/ SS patients. Unsupervised k-means clustering was applied to the immunological features of the combined patient cohorts and two distinct patient endotypes, were identified: Group-1 ( $n=49 ; p S S=24, S L E=19, S L E / S S=6)$ and Group-2 ( $n=39 ; p S S=21, S L E=10, S L E / S S=8)$. Significant differences in immune-cell phenotypes across B-cell and T-cell subsets were identified by logistic regression, BRF ( $A U C=0.9942$, assessed by 10 -fold cross-validation) and SPLS-DA analysis. Comparison of the multiple analysis approaches identified eight common immune-cell subsets, including total and memory CD4+ and CD8+ T-cell subsets but no B-cell subsets. Using this common immune-signature the stratification between the groups was maintained and slightly improved (AUC=0.9979 and accuracy $96.16 \%$ ). Interestingly, patients in Group-2 had elevated disease activity measures at baseline and over a 5 -year trajectory compared to Group-1. Finally, correlation analysis identifed correlations between disease activity markers and the top ranked immune features from the ML models.

Conclusion: The identified immune-cell signatures could reflect the underlying disease pathogenesis that spans diagnositc criteria and could be used to select patients for targeted therapeutic approaches.

Acknowledgements: $L M-G$ is supported by a project grant from The Dunhill Medical Trust (RPGF19021117); JP is supported by Versus Arthritis (21226). GAR is supported by Lupus UK, The Rosetrees Trust (M409) and Versus Arthritis (21593). MN is supported by NIHR UCLH Biomedical Research Centre (BRC525/III/CC/191350). HP has a Versus Arthritis PhD studentship (22203). This work was performed within the Centre for Adolescent Rheumatology Versus Arthritis at UCL UCLH and GOSH supported by grants from Versus Arthritis (21593 and 20164), GOSCC, and the NIHR-Biomedical Research Centres at both GOSH and UCLH.
We would like to thank Mr Jamie Evans for expert support with flow cytometry analysis and Ms Eve McLoughlin for support with patient recruitment.

Disclosure of Interests: None declared

DOI: 10.1136/annrheumdis-2021-eular.2434

\section{POS0175 ASSOCIATION BETWEEN BIOMARKERS AND THERAPEUTIC PATHWAY IN PATIENTS WITH SLE}

S. U. Hassan ${ }^{1,2}$, K. Mahmoud $^{1,2}$, Z. Wigston ${ }^{1}$, A. Burska ${ }^{1}$, M. Y. MD Yusof ${ }^{1,2}$, E. Vital ${ }^{1,2} .{ }^{1}$ Leeds Institute of Rheumatic and Musculoskeletal Medicine, Rheumatology, Leeds, United Kingdom; ${ }^{2} \mathrm{NIHR}$ Leeds Musculoskeletal Biomedical Research Centre, Leeds Teaching Hospitals NHS Trust, Leeds, United Kingdom

Background: SLE is heterogeneous in clinical presentation, underlying immunology, and response to therapy. Patients with severe or resistant disease receive cyclophosphamide or rituximab. Although effective, late use of these therapies entails cumulative damage.

Emerging predictors of response to rituximab include demographics, IFN-Scores and autoantibodies. For such predictors to change treatment strategy we need to understand their association with the effectiveness of other therapeutic options at earlier decision points.

Prospective studies of treatment pathways are difficult to perform, requiring large populations followed for many years. We therefore investigated this question by analysing retrospective treatment pathways since diagnosis in patients whose biomarker status is subsequently known.

Objectives: To use interferon scores and other markers to;

[1] identify SLE patients more likely to need escalation of therapy to either rituximab or cyclophosphamide, and

[2] determine if this occurred sooner than in others.

Methods: In patients with established SLE, attending Leeds SLE clinic, we collected demographics, clinical characteristics and blood at a single timepoint. Two previously validated IFN-Scores[1,2] (IFN-Score A and IFN-Score B) were measured using Taqman. Autoantibodies were measured using immunoprecipitation. Treatment history covering all antimalarials, oral and intravenous immunosuppressants (agent, start and stop dates and reasons) since diagnosis was collected. Univariable and multivariable Cox proportional hazards models were used to test variables as predictors of the primary endpoint: time to cyclophosphamide/ rituximab.

Results: 124 patients were included. Follow up since diagnosis was Median (IQR) 37.5 (27.4-52.3) years, total therapies per patient was 3 (1-4), therapies per year was 0.2 (0.1-0.3). 54/124 (44\%) patients required cyclophosphamide/ rituximab.

Results of Cox regression are shown in the table 1. There was a significan association between high expression of IFN-Score B and requirement for cyclophosphamide/rituximab as well as trends for age in the first quartile ( $<28$ years), IFN-Score A and anti-Sm/U1RNP antibodies. Both age $<28$ and IFN-Score B retained trends as independent predictors in a multivariable model.

Table 1.

\begin{tabular}{|c|c|c|c|c|c|c|}
\hline Characteristic & $\begin{array}{c}\text { CYC/ } \\
\text { RTX=Yes } \\
n(\%)\end{array}$ & $\begin{array}{c}\text { CYC/ } \\
\text { RTX = } \\
\text { No n(\%) }\end{array}$ & $\begin{array}{c}\text { Univariable } \\
\text { Hazard ratio } \\
(95 \% \mathrm{Cl})\end{array}$ & $\begin{array}{c}\text { Univariable } \\
\mathrm{p} \text { value }\end{array}$ & $\begin{array}{l}\text { Multivariable } \\
\text { Hazard Ratio } \\
(95 \% \mathrm{Cl})\end{array}$ & $\begin{array}{c}\text { Multivariable } \\
\text { p value }\end{array}$ \\
\hline \multicolumn{7}{|l|}{ Age } \\
\hline -Q1: under 28 & $22(71 \%)$ & $9(29 \%)$ & $\begin{array}{c}2.25 \\
(0.99,5.12)\end{array}$ & 0.054 & $\begin{array}{c}1.74 \\
(0.95,3.18)\end{array}$ & 0.074 \\
\hline$-Q 2: 28-38$ & $12(39 \%)$ & $19(61 \%)$ & $\begin{array}{c}1.03 \\
(0.41,2.56)\end{array}$ & 0.949 & Not included & Not included \\
\hline -Q3: $38-52$ & $12(39 \%)$ & $19(61 \%)$ & $\begin{array}{c}1.52 \\
(0.62,3.72)\end{array}$ & 0.360 & Not included & Not included \\
\hline $\begin{array}{l}\text {-Q4: over } 52 \\
\text { Ethnicity }\end{array}$ & $8(26 \%)$ & $23(74 \%)$ & reference & reference & Not included & Not included \\
\hline -Caucasian & 42 (48\%) & $46(52 \%)$ & $\begin{array}{c}1.17 \\
(0.58,2.35)\end{array}$ & 0.660 & Not included & Not included \\
\hline $\begin{array}{l}\text {-AfroCaribbean, } \\
\text { South Asian, } \\
\text { East Asian, } \\
\text { Other }\end{array}$ & $10(36 \%)$ & $18(64 \%)$ & reference & reference & & \\
\hline $\begin{array}{l}\text { IFN Score A, } \\
\text { mean (SD) }\end{array}$ & $\begin{array}{l}-2.59 \\
(-2.67)\end{array}$ & $\begin{array}{l}-3.84 \\
(-2.71)\end{array}$ & $\begin{array}{c}1.10 \\
(0.98,1.24)\end{array}$ & 0.113 & Not included & Not included \\
\hline $\begin{array}{l}\text { IFN Score B, } \\
\text { mean (SD) }\end{array}$ & $\begin{array}{l}-2.61 \\
(-1.16)\end{array}$ & $\begin{array}{l}-3.53 \\
(-1.76)\end{array}$ & $\begin{array}{c}1.31 \\
(1.05,1.64)\end{array}$ & 0.017 & $\begin{array}{c}1.23 \\
(0.98,1.55)\end{array}$ & 0.079 \\
\hline $\begin{array}{c}\text { Anti-Sm/U1RNP } \\
\text { Ab positive }\end{array}$ & $17(61 \%)$ & $11(39 \%)$ & $\begin{array}{c}1.50 \\
(0.84,2.67)\end{array}$ & 0.171 & Not included & Not included \\
\hline $\begin{array}{l}\text { Anti-Ro(60) Ab } \\
\text { positive }\end{array}$ & $14(45 \%)$ & $17(55 \%)$ & $\begin{array}{c}0.88 \\
(0.47,1.65)\end{array}$ & 0.686 & Not included & Not included \\
\hline
\end{tabular}

